\title{
Recruitment Variability of Small Pelagic Fish Populations in the Kuroshio-Oyashio Transition Region of the Western North Pacific
}

\author{
Yoshiro Watanabe \\ 1 Ocean Research Institute, the University of Tokyo, \\ 1-15-1 Minamidai, Nakanoku, Tokyo 164-8639, Japan \\ ywatanab@ori.u-tokyo.ac.jp
}

Watanabe, Y. 2009. Recruitment Variability of Small Pelagic Fish Populations in the KuroshioOyashio Transition Region of the Western North Pacific. J. Northw. Atl. Fish. Sci., 41: 197-204. doi:10.2960/J.v41.m635

\begin{abstract}
Climatic and ecosystem changes in the transition region between the subarctic Oyashio and the subtropical Kuroshio Extension fronts may be the key to understanding recruitment variability of small pelagic fish populations in the Pacific waters off Japan. The transition region is characterized by complex oceanographic structure with the meandering fronts, eddies and streamers creating large spatial and temporal variability in the environment. Juveniles of small pelagic fishes such as Japanese sardine (Sardinops melanostictus), Pacific saury (Cololabis saira), and Japanese anchovy (Engraulis japonicus) migrate from the subtropical Kuroshio Current area to the subarctic Oyashio Current area across the transition region. A precipitous decline in number of age 0 recruits of Japanese sardine after the end of 1980 s appears to be related to the extremely high mortality rate of young-of-the-year fish in the transition region. In contrast, populations of Pacific saury and Japanese anchovy increased after 1988. These synchronous changes in populations seem to be associated with the weakening of the Aleutian Low Pressure in the North Pacific and weakening of the Oyashio Current in winter, and a sea surface temperature (SST) rise in the Kuroshio-Oyashio transition region in spring. The contrasting responses of the fish populations to the SST rise can be explained by different temperature preference in terms of growth rate in larval and early juvenile stages; cool temperatures are preferred by sardine and warm temperatures are preferred by saury and anchovy.
\end{abstract}

Keywords: climate change, Japanese sardine, Japanese anchovy, Pacific saury, synchronous changes

\section{Introduction}

Small pelagic fish populations have shown large fluctuations in the world oceans. These fluctuations of different populations seem to be synchronous within the California, Humboldt, and Kuroshio-Oyashio Current systems, as well as between the systems (Schwartzlose et al., 1999). Synchronous changes of fish populations are recognized to be associated with climatic and marine ecosystem changes in the North Pacific Ocean (Chavez et al., 2003).

In the Kuroshio-Oyashio Current system in the Pacific waters off Japan (Fig. 1), the Pacific stock of Japanese sardine (Sardinops melanostictus) experienced a precipitous decline in the 1990 s after the historical peak catch of 2.9 million metric tons $(t)$ in 1987 to less than $1 \%$ of this peak in the 2000s in Japan (Fisheries Research Agency, 2007). In contrast, the catches of the Pacific saury (Cololabis saira) and the Pacific stock of Japanese anchovy (Engraulis japonicus) increased after the end of 1980s (Fisheries Research Agency, 2007). These small pelagic fishes spawn in the Kuroshio Current area off southern Japan. Eggs and larvae are rapidly transported to the downstream Kuroshio Extension area by the prevailing current (Heath et al., 1998). In the spawning ground, abundance of eggs, yolk-sac larvae, and post-first-feeding larvae of Japanese sardine were positively correlated with each other (Watanabe et al., 1995).

I hypothesize that recruitment of small pelagic fishes may be determined not in the Kuroshio Current area, but in the downstream Kuroshio-Oyashio transition region in the Pacific waters off northern Japan. Juveniles of the small pelagic fishes migrate north from the subtropical Kuroshio Current area to the subarctic Oyashio Current area across the transition region, a region of about $500 \mathrm{~km}$ wide and encompassing a $10^{\circ} \mathrm{C}$ temperature gradient, in spring 


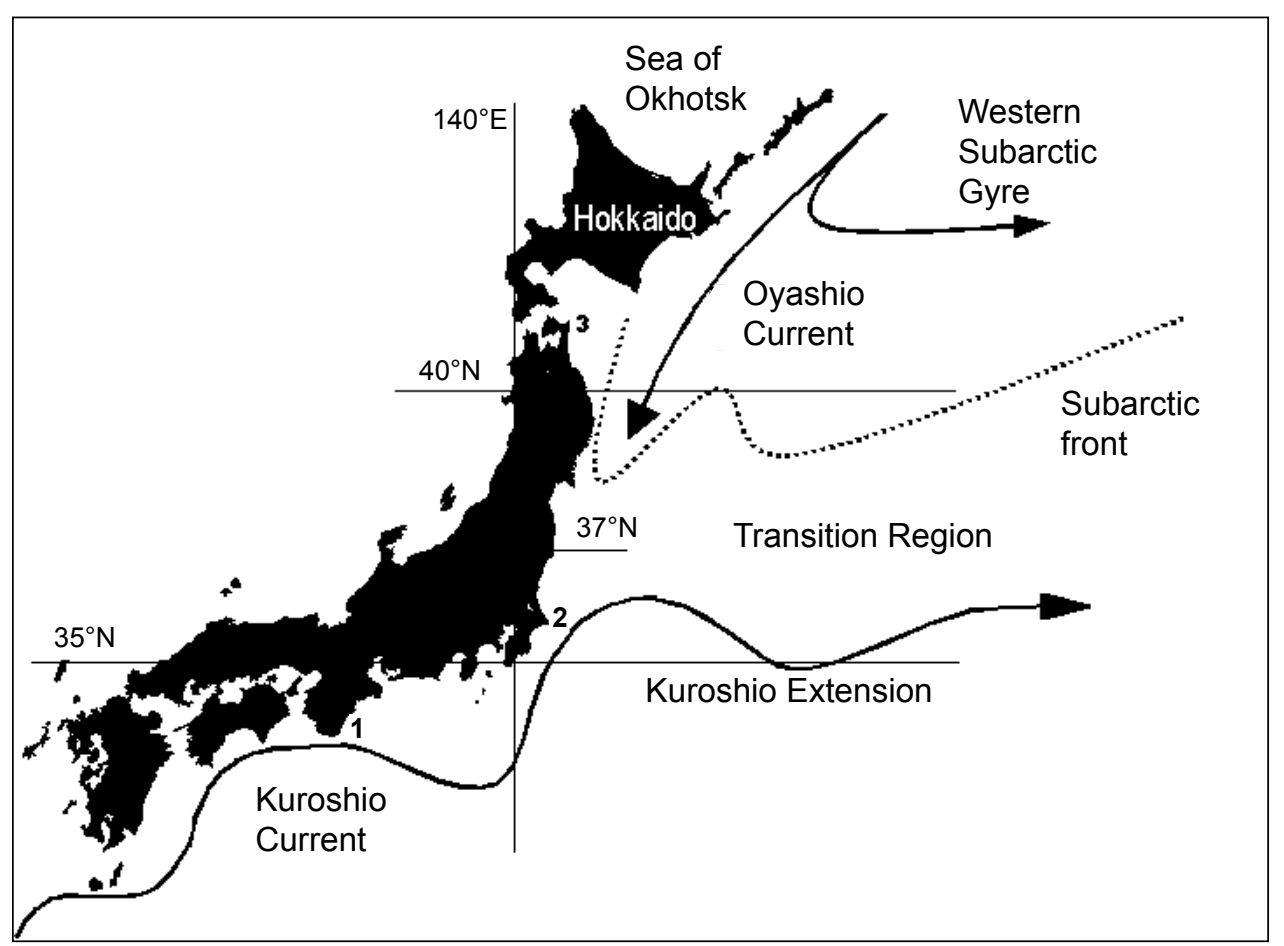

Fig. 1. Synoptic oceanography in the Pacific waters off Japan. Numerals represent locations of the capes separating the fishing area; 1. represents Cape Shionomisaki, 2. Cape Inubozaki, and 3. Cape Shiriyazaki.

and early summer. They feed on abundant zooplankton in the northern transition region and the Oyashio Current area in summer. The oceanographic environments of the transition region are seasonally and interannually variable (Yasuda, 2003), which can have deep impacts on growth and survival processes in the late larval and juvenile stages and eventual recruitment to adult population. Interannual variations in vital parameters in early life stages were substantial in the cohorts of Pacific saury spawned in the transition region (Watanabe et al., 1997, 2003). Cumulative survival from egg to age 1 recruits of Japanese sardine was strongly associated with sea surface temperature (SST) in the Kuroshio Extension area during the years of population increase and decline (Noto and Yasuda, 1999).

The Kuroshio-Oyashio transition region exists between the Kuroshio Extension Front, defined as $14^{\circ} \mathrm{C}$ at $200 \mathrm{~m}$ depth, and the subarctic Front, defined as $4^{\circ} \mathrm{C}$ at $100 \mathrm{~m}$ depth, off the Pacific coast of northern Japan (Fig. 1; Yasuda, 2003). The Kuroshio Extension is a strong jet of the dominant western boundary current, the Kuroshio Current, of the North Pacific Subtropical Gyre. The Oyashio Current originates from the East Kamchatka Current, which is a part of the western subarctic gyre flowing southwestward from the Bering Sea. The East Kamchatka
Current merges with the outflow of the Okhotsk Sea water and forms the Oyashio Current, flowing further southwestward near to the Pacific coast of northern Japan. Situated between the major oceanic fronts, the transition region is largely affected by latitudinal shifts of the fronts and by occurrence and movements of eddies and streamers associated with the meandering fronts (Yasuda, 2003).

In this review, I describe in detail of the population fluctuations of the Pacific stock of Japanese sardine, Pacific saury, and the Pacific stock of Japanese anchovy in the last three decades, and demonstrate that the drastic population changes of these three fish species occurred at the same time in the end of the 1980s. The close association between the fish population changes and both the oceanographic changes in the Kuroshio-Oyashio transition region and the climatic change in the North Pacific Ocean will be depicted as a notable example of a direct climate-ocean-fish population linkage.

\section{The Pacific Stock of Japanese Sardine}

Spawning stock biomass (SSB) of the Pacific stock of Japanese sardine increased during the end of the 1970s and middle 1980s and peaked at 13.4 million $\mathrm{t}$ in 1988, but declined precipitously thereafter down to 0.22 million $t$ in 

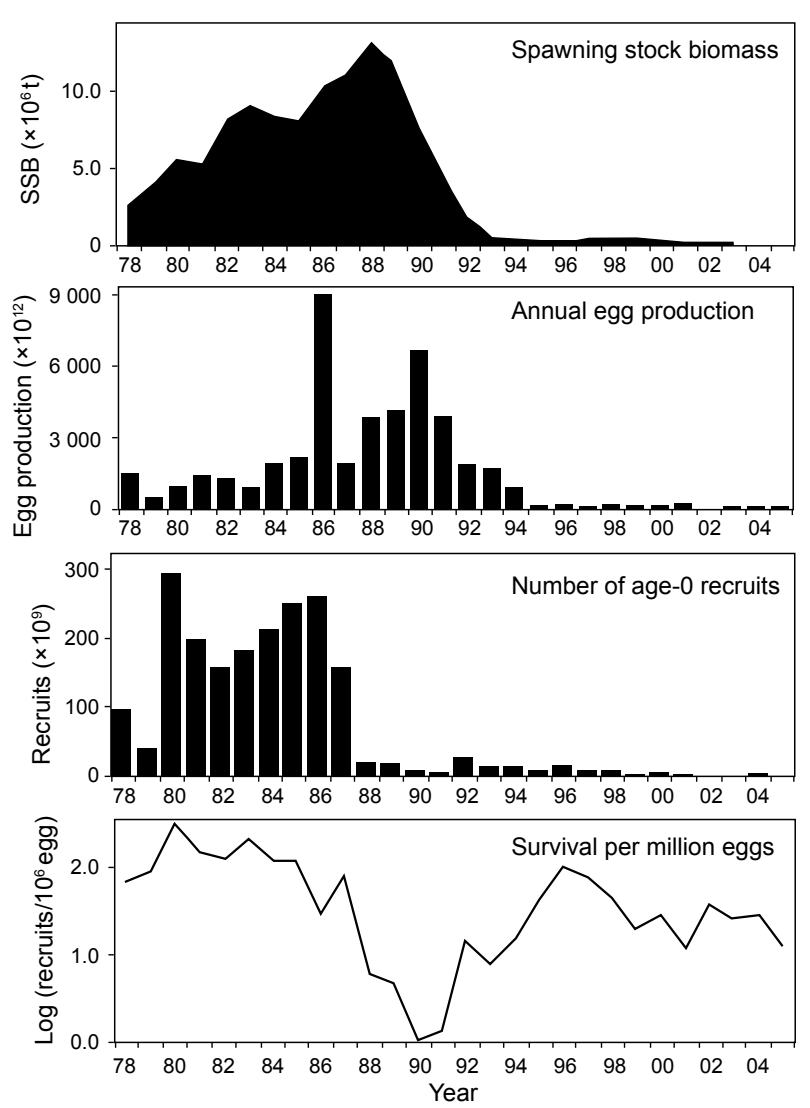

Fig. 2. The Pacific stock of Japanese sardine (Sardinops melanostictus), showing spawning stock biomass, annual egg production, number of age- 0 recruits, and survival in terms of number of age- 0 recruits per 1 million eggs produced, from 1978 to 2005.

1996 (Fig. 2; Fisheries Research Agency, 2007). The precipitous decline of the population began with the sudden decreases in number of age- 0 recruits in the end of the 1980s. Average number of age- 0 recruits was as high as $213.3 \pm 2.4$ billion during $1980-1987$, but remarkably decreased after 1988 to a mean of $14.2 \pm 2.4( \pm \mathrm{SD})$ billion during 1988-1995 (Fig. 2).

The decreases in number of age- 0 recruits after 1988 were not the results of low egg production but rather of low survival of young-of-the-year (YOY) fish. Annual total egg production of the Pacific stock of Japanese sardine increased in the $1980 \mathrm{~s}$ and stayed at the maximum level of $3800,4000,6700$, and 3900 trillion in 1988, 1989, 1990, and 1991, respectively (Fig. 2; Fisheries Research Agency, 2007), with the exception of the exceptionally high estimate in 1986. In spite of the high egg productions, the number of age- 0 recruits declined in the four consecutive years owing to the extremely low cumulative survival rate from egg stage to recruitment. Number of age-0 recruits that survived per 1 million eggs produced was as high as $120-310$ during $1980-1985$, which produced large numbers of age- 0 recruits $(215 \pm 49$ billion) that resulted in the steady increase of SSB in the early and middle 1980s. The survival rates decreased somewhat to a moderate level of 29 and 84 in 1986 and 1987, respectively, but suddenly dropped to about 6.0 in 1988 and 4.8 in 1989. The number of recruits further declined to around 1.0 in 1990 and 1991. These low survival rates of YOY during 1988 and 1991 were devastating to the population, and led to the SSB decline after 1990. The survival rate somewhat recovered to $7.3-15$ recruits per 1 million eggs produced during 1992-1994, but SSB had declined to $14-4 \%$ of the peak in these years. Therefore, annual egg productions also decreased to 630 trillion in 1994. The survival rate further recovered to 42-110 during 1995-1998, but SSB was only $2-4 \%$ of the peak in 1988 and the annual egg production had reduced to $140 \pm 34$ trillion. The population never produced a large number of recruits in these years. SSB steadily declined in the 2000 s, from 0.23 in 2000 to 0.07 million $t$ in 2005 , in spite of moderate survival rate of 11-37 recruits per 1 million eggs produced. The further decline in SSB is considered to be a result of high fishing mortality by purse seiners (Watanabe, 2007a).

The recruitment failure of Japanese sardine during the end of the 1980s and the beginning of the 1990s could not be explained by high mortality in the first feeding stage. When abundance of post-first feeding larvae of 6-8 $\mathrm{mm}$ notochord length in the spawning grounds are plotted against annual egg production of the stock for 13 years from 1978 to 1990, a significant positive correlation was detected (Watanabe et al., 1995). Even in the 3 years (1988-1990) of low survival from egg stage to age-0 recruitment (Fig. 2), the abundance of post first feeding larvae was high and clearly proportional to the large egg production. The high mortality from egg stage to age- 0 recruitment experienced by the three year classes did not occur in the first feeding stage up to 6-8 $\mathrm{mm}$ body length at approximately two weeks after fertilization in the spawning ground. The recruitment failure of these year classes was apparently materialized by high mortality after the first feeding stage (Watanabe et al., 1995).

The Pacific stock of Japanese sardine spawns in the subtropical Kuroshio Current area along the Pacific coast of southern Japan mostly in February and March (Watanabe et al., 1996; Oozeki et al., 2007). Eggs and larvae are rapidly transported northeastward by the current and reach the waters off Cape Inubozaki in central Japan in 2-3 weeks (Heath et al., 1998). Sardine larvae are further transported by the Kuroshio Extension to the offshore waters of central Japan. They metamorphose to juveniles 
in 30-40 days after hatching (Watanabe and Saito, 1998). Sardine juveniles migrate north across the transition region along the warm water streamers originating from the Kuroshio Extension in early summer (Sugisaki et al., 1996; Takahashi et al., 2008b), and reach the Oyashio Current area in summer. Age-0 recruits usually appear in the fishing ground off eastern Hokkaido in August (Wada, 1988). The Kuroshio-Oyashio transition region seems to be a key area to understanding large variations in survival of YOY sardine.

\section{Synchronous Changes}

Large magnitudes of population changes occurred in the other small pelagic fishes in the end of the 1980s. Pacific saury is one of the important pelagic fish species in the western North Pacific, exploited by Japan, Russia, and Korea. The major fishing grounds of saury are located in the Oyashio Current area and the transition region off northern Japan. Annual catch of saury in Japan during 1978-2005 averaged ( \pm SD) $240 \pm 51$ thousand $t$ (Fisheries Research Agency, 2007). Catch-per-unit-effort (CPUE), as an index of population density, averaged ( \pm SD) $10.4 \pm 2.8 \mathrm{t}$ per fishing boat per night during 1978 and 1987, but jumped up to $25.4 \mathrm{t}$ in 1988 and averaged $28.5 \pm 7.4 \mathrm{t}$ in the next 10 years between 1988 and 1997 (Fig. 3, Tohoku National Fisheries Research Institute, 2007). CPUE decreased to the level before 1987 in 1998 and subsequent years.

Pacific saury migrates north and south across the Kurosio-Oyashio transition region (Fukushima, 1977; Watanabe and Lo, 1989). Adult saury move southward from the feeding grounds in the Oyashio Current area to the transition region in the end of summer and spawn there in autumn. They further move to the southern Kuroshio Current area and continue spawning in this area in winter. They return to the transition region and continue spawning until early summer. Early life parameters such as daily growth and instantaneous mortality rates and resulting preschooling juvenile productions of the saury are generally stable in the subtropical Kuroshio Current area in winter,

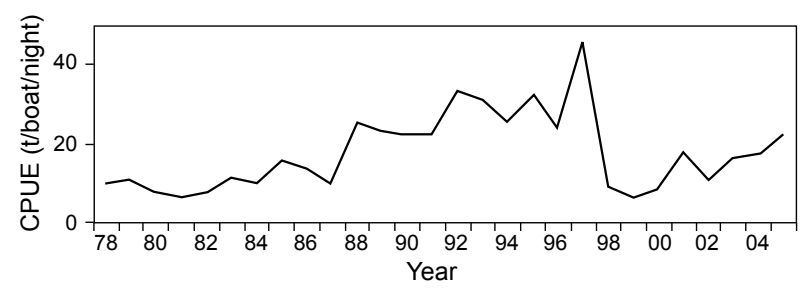

Fig. 3. Pacific saury (Cololabis saira), showing catch in metric tons per fishing boat per night operation (CPUE) from 1978 to 2005 . but variable in the transition region in autumn and spring (Watanabe et al., 1997, 2003). As a large proportion of the saury exploited in the fishing season during August and December is up to 1 year old (Fukushima et al., 1990), the increase in CPUE of the saury in 1988 was due to increased recruitment of age- 0 fish, most probably of the autumn and spring spawned cohorts with large variability in the transition region.

Population increase after the end of the 1980s was also seen in the Pacific stock of Japanese anchovy. Number of anchovy age- 0 recruits averaged $33.8 \pm 7.8( \pm \mathrm{SD})$ billion during 1980 and 1987, but increased to 74.8 billion in 1988 and averaged $96.9 \pm 35.0$ billion between 1988 and 1995 (Fig. 4; Fisheries Research Agency, 2007). The recruitment increase directly paralleled catch increase of
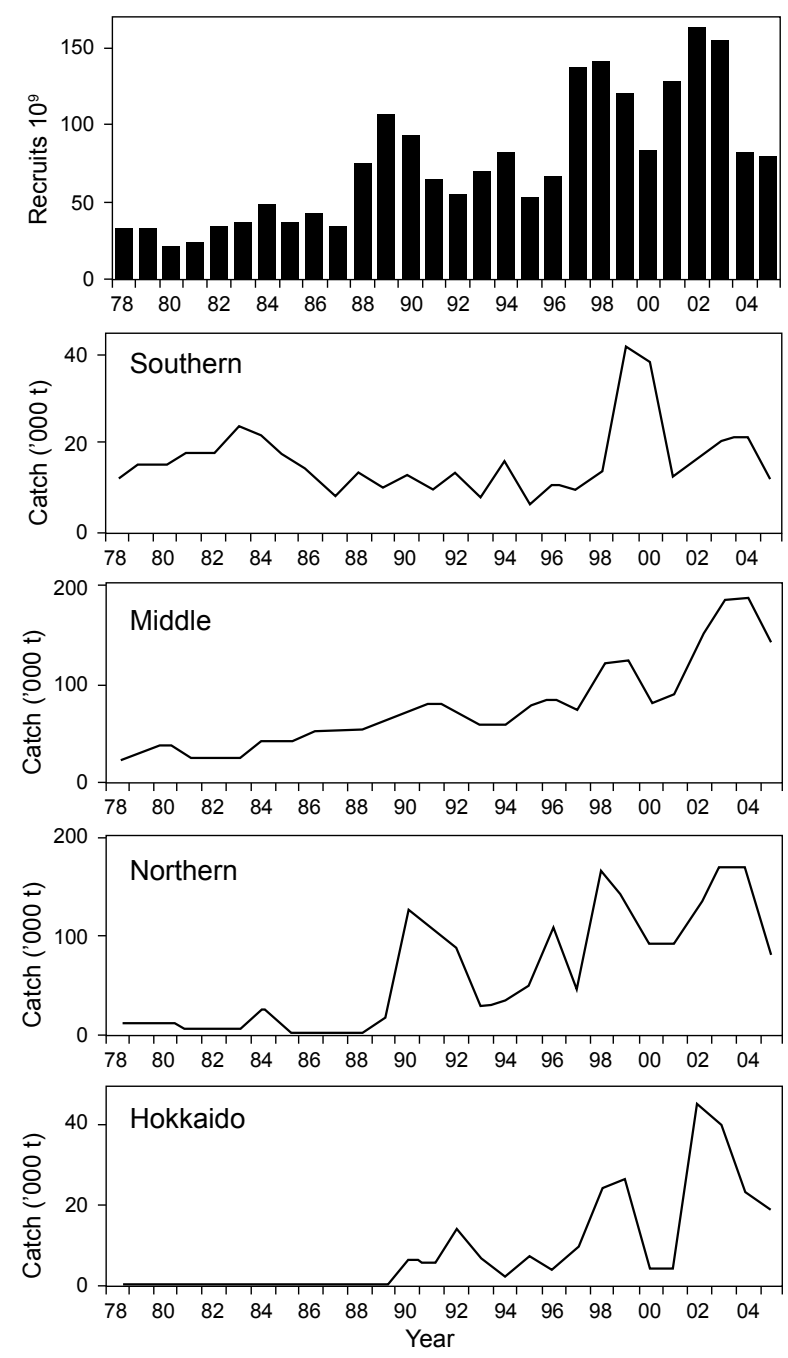

Fig. 4. The Pacific stock of Japanese anchovy (Engraulis japonicus), showing number of recruits, and annual catches in metric tons in the southern, middle, northern, and Hokkaido fishing areas from 1978 to 2005. 
anchovy after 1990. When the fishing ground of the Pacific stock of Japanese anchovy is separated into four latitudinal areas, a clear north-south difference in the magnitude of variability can be seen (Fig. 4). In the southern fishing area southwest of Cape Shionomisaki at $33^{\circ} \mathrm{N}$ (Fig. 1), anchovy catch averaged $15.5 \pm 4.7$ thousand t during 1978 and 89 and did not increased much after 1990, with the average of $16.4 \pm 10.1$ thousand t during 1990 and 2005 (Fisheries Research Agency, 2007). In the middle fishing area between Cape Shionomisaki and Cape Inubozaki at $35^{\circ} 40^{\prime} \mathrm{N}$, the catch averaged $39.2 \pm 13.2$ thousand t during 1978-1990 and more than doubled to $103.5 \pm 42.0$ during 1991-2005. In the northern fishing area between Cape Inubozaki and Cape Shiriyazaki at $41^{\circ} 30^{\prime} \mathrm{N}$, in which the transition region is included, the catch increased by more than one order of magnitude from $8.2 \pm 6.6$ in the 12 years to $100.8 \pm 46.7$ thousand tons in the 16 years. In the northern most fishing area in the Oyashio Current area off Hokkaido Island, the increase was most remarkable from $0.1 \pm 0.1$ thousand $\mathrm{t}$ to $15.0 \pm 13.4$ thousand $\mathrm{t}$, more than two order of magnitude.

Variability in catches of Japanese anchovy was large in the northern fishing areas. CVs in annual catch in each of the 4 fishing areas during the 28 years from 1978-2005 were $0.51,0.60,0.96$, and 1.45 , respectively. As the catches in the northern and Hokkaido fishing areas were as small as 8.2 and 0.1 thousand t before 1988, respectively, large variability in catches in the northern and Hokkaido fishing areas seem to have resulted from the northward expansion of the distributional range of the anchovy stock with the high recruitment success after the 1988 year-class.

The population trends of these small pelagic fishes changed simultaneously in 1988 . These three species seem to have responded to common environmental changes occurring in the transition region in the western North Pacific.

\section{Oceanographic Changes in the Transition Region}

A decadal climate shift occurred in the North Pacific at the end of the 1980s (Minobe and Mantua, 1999). The North Pacific Index (NPI) provides a measure of the intensity of the mean wintertime Aleutian Low Pressure. It is calculated as the area-weighted sea level pressure over the region $30-65^{\circ} \mathrm{N}, 160^{\circ} \mathrm{E}-140^{\circ} \mathrm{W}$. The three-year running mean of the index ranged from -0.65 to -1.29 during 1980-1987, but increased to -0.05 in 1988 and stayed positive over the next three years from 1989 to 1991 . It then returned to around zero in the following four years
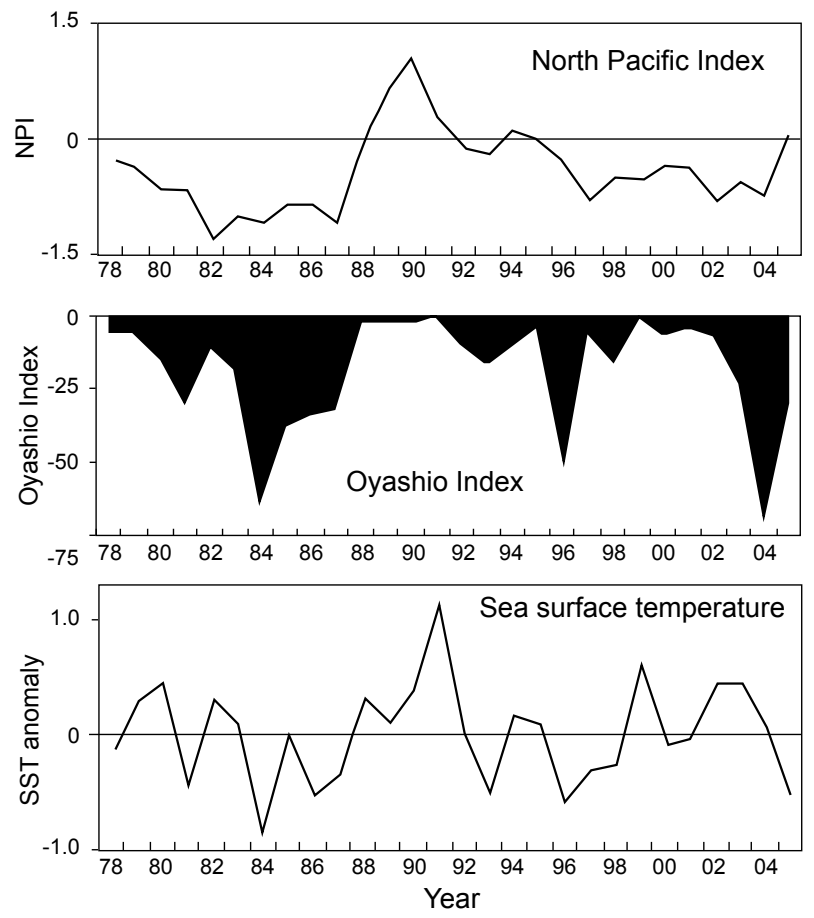

Fig. 5. North Pacific Index (NPI), Oyashio Index (see text), and sea surface temperature (SST) anomaly, in the transition region in April and May.

and decreased to less than -0.3 after 1996 (Fig. 5). These changes indicate that Aleutian Low Pressure was strong from 1980 and 1987, but weakened remarkably during 1988-1991, and then stayed at the moderate level.

In the western North Pacific, a clear oceanographic response to the decadal NPI change was detectable. Sea surface temperature (SST) in the Pacific waters off northern Japan in winter and spring is largely affected by the latitudinal shift of the Oyashio Current (Yasuda, 2003). Strength of the southward intrusion of the Oyashio Current can be indexed by the area with SST $<10^{\circ} \mathrm{C}$ south of the $37^{\circ} \mathrm{N}$ line in the longitudes ranging from $140^{\circ}$ to $150^{\circ} \mathrm{E}$ (Ebisawa and Kinoshita, 1998). They examined interannual change in the index during February and March and found that the Oyashio Current extended south beyond the $37^{\circ} \mathrm{N}$ line during $1980-1987$, but retreated north to around the $37^{\circ} \mathrm{N}$ line in $1988-1991$, then recovered somewhat to its southerly-extending mode after 1992 (Fig. 5). SST anomalies in April and May in the transition region between $35-40^{\circ} \mathrm{N}$ from the 28 year mean (1978-2005) tended to be zero or negative during 1980-1987, but turned positive during the four consecutive years from 1988-1991, and then returned to around zero after 1992. In the western North Pacific, variation in the strength of the Aleutian Low Pressure in winter seems to have resulted in variation in the southern extension of the Oyashio Current 
in winter (Yasuda, 2003), which eventually affects SST in spring in the transition region (Fig. 5).

The transition region shifted from relatively cold to warm conditions in 1988 and the population trends of the small pelagic fishes changed synchronously in this year; survival of YOY sardine declined, population density of Pacific saury increased, and recruitment of Japanese anchovy increased. It is unknown whether the latitudinal shift of the Oyashio Current and/or SST change in the transition region had direct effects on survival and recruitment of these pelagic fishes. SST rise in the transition region can cause decreases in the magnitude of vertical mixing of the water column and nutrients supply from the deeper aphotic layers in winter, and result in low biological productivity in spring. Unfavorable feeding conditions for juvenile Japanese sardine might have occurred in the transition region in the warm years after 1988. However, these three species are all planktivores. The contrastive population changes with the SST rise cannot simply be explained by the change in zooplankton abundance in the transition region.

Although the main hypothesis of this paper is that recruitment of small pelagic fishes may be determined in the Kuroshio-Oyashio transition region in the Pacific waters off northern Japan, an alternative hypothesis of the drastic fish population dynamics can be mass mortality of larvae in the spawning grounds in the Kuroshio Current area off southern Japan. Nakai (1962) assumed that the population decline of Japanese sardine in the 1940s occurred owing to high mortality of early larvae in the Kuroshio Current area. The observed abundances of eggs and early larvae reported by Watanabe et al. (1995) in the 1980s and early 1990s, however, clearly indicated that recruitment determination of Japanese sardine did not occur in the spawning grounds along the Kuroshio Current. Recently, Takasuka et al. (2008) demonstrated the species-specific spawning temperature preferences of Japanese sardine $\left(16^{\circ} \mathrm{C}\right)$ and anchovy $\left(22^{\circ} \mathrm{C}\right)$, chub mackerel (Scomber japonicus) $\left(18^{\circ} \mathrm{C}\right)$, and jack mackerel (Trachurus japonicus) $\left(22^{\circ} \mathrm{C}\right)$, and proposed a hypothesis that direct temperature impacts on vital parameters of eggs and larvae in the spawning grounds can be a cause of multi-species regime shifts of small pelagic fishes. However, no clear regime shift signal was detected in the egg-density-weighted mean SST as a proxy of actual temperature experienced by the populations of the sardine (18.0-19.0 $0^{\circ} \mathrm{C}$ during $1985-1993$ and $17-18^{\circ} \mathrm{C}$ during 1994-1999) and anchovy (around $22^{\circ} \mathrm{C}$ during 1984-1989 and $20^{\circ} \mathrm{C}$ during 1989-1999) (Takasuka et al., 2007). In general, the environmental conditions of the spawning grounds of sardine and anchovy in the Kuroshio Current area are relatively stable compared to the northern tran- sition and Oyashio regions. The coefficient of variation of annual mean SST during 1950-2000 was 0.07 in the Kuroshio Current region, much smaller than that in the transition region (0.24) or in the Oyashio region $(0.21)$ (Tian et al., 2003). Thus, species-specific spawning temperature preferences probably do not constitute the major cause of the contrasting fish population dynamics detected over the last several decades.

Growth performances of sardine and anchovy are closely associated with temperature in opposite manners. Takasuka and Aoki (2006) and Takasuka et al. (2007) examined correlations between the larval growth rate in the 3 days prior to collection and SST at the collection sites, and demonstrated that optimum temperatures for growth of Japanese sardine (8.0-33.4 mm SL) and Japanese anchovy larvae (6.4-34.3 mm SL) collected in the East China Sea, the Kuroshio Current area and the downstream Kuroshio Extension and the Kuroshio-Oyashio transition region were different from each other, i.e., $16^{\circ} \mathrm{C}$ for sardine and $21^{\circ} \mathrm{C}$ for anchovy. They interpreted that the different preference to temperature in terms of larval growth rate was considered to be a key factor of differential responses to the SST rise in the transition region after 1988. As has been reported in larval and early juvenile Pacific saury, the recent growth rate in length was largely affected by fish body length itself (Oozeki et al., 2004). Because growth rates in length tend to slow down in the late larval stage in Japanese sardine (Watanabe and Kuroki, 1997; Watanabe and Nakamura, 1998) and Japanese anchovy (Takahashi et al., 2001; Takahashi and Watanabe, 2004a), we need to consider body length as a factor in growth rate for a more detailed discussion on the effects of temperature on fish growth rates.

Growth rate in early life stages is considered to be a principal factor of recruitment determining process (Houde, 1987; Bailey and Houde, 1989). This seems to be especially true in late larval and early juvenile stages. Frequency distribution of growth rates after the onset of metamorphosis of Japanese anchovy tended to shift to the faster rates with the progress of metamorphosis in the Kuroshio-Oyashio transition region (Takahashi and Watanabe, 2004a, b). These observations indicated that the fast growing anchovy had a higher probability of survival in the metamorphosing stage and successfully recruited to adult population in the region. Recruitment of Japanese sardine was also dependent on growth rates in the juvenile stage in the transition region (Takahashi et al., 2008). Takahashi (personal communication, Seikai National Fisheries Research Institute, Nagasaki 851-2213, Japan) examined growth rates of metamorphosing sardine and anchovy collected in the transition region and found that growth rate decreased in sardine and increased in anchovy 
with the SST rise in spring. The opposite responses in growth rate to SST changes between sardine and anchovy can be a recruitment determining mechanism working through growth rate selective survival during late larval and juvenile stages of these clupeoid species.

As for Pacific saury, the SST rise in the transition region could favor growth and survival in early life stages. Four species of sauries (Scomberesocidae) are distributed in the world oceans (Hubbs and Wisner, 1980). They are members of order Belonidae together with flying fishes and halfbeaks, and were originally warm water species. Larval and juvenile Pacific saury showed an increase in growth rate with an experimental temperature rise up to $24^{\circ} \mathrm{C}$ (Oozeki et al., 2004). The weaker Oyashio Current in winter and the SST rise in the transition region in spring after 1988 (Fig. 5) could have favored growth and survival and probably eventual recruitment of the transition region spawned cohorts of Pacific saury, leading to the increase in CPUE of the saury. The decline in CPUE of saury after 1998 could not be explained by warm SST during 1999-2004.

The climatic changes in the North Pacific, oceanographic changes in the transition region, and population trends of the small pelagic fishes in the Pacific waters off Japan in the last quarter century are typical example of the close linkage of climate - ocean - fish populations. The linkage is not limited to small pelagic fish species. In some groundfishes, such as Tanakius kitaharai, Hippoglossoides dubius, and Lophiomus setigerus, CPUE by Japanese bottom trawlers increased greatly in the 1990s after the low period in the 1980s in the coastal and offshore waters in the transition region (Nihira et al., 2003). The climate - ocean - fish population linkage seems to be a universal phenomenon irrespective of pelagic and bottom dwelling fish species in this transition region with a steep latitudinal gradient in environmental conditions between the subtropical and subarctic water domains (Watanabe, 2007b).

\section{Acknowledgements}

M. Takahashi, A. Takasuka, and Y. Oozeki helped the author in preparing the presentation of this paper in the symposium. Y. Ebisawa provided the author with the recent Oyashio Index data. The COST program partly supported the author's travel to Lisbon to present at the symposium.

\section{References}

BAILEY, K. M., and E. D. HOUDE. 1989. Predation on eggs and larvae of marine fishes and the recruitment problem. Adv. Mar.
Biol., 25: 1-83. doi:10.1016/S0065-2881(08)60187-X

CHAVEZ, F. P., J. RYAN, S. E. LLUCH-COTA, and M. NIQUEN. 2003. From anchovies to sardines and back: multidecadal change in the Pacific Ocean. Science, 299: 217-221. doi:10.1126/science. 1075880

EBISAWA, Y., and T. KINOSHITA. 1998. Relationship of surface water temperature in Boso - Sanriku area sea and recruitment per spawning biomass of the Japanese sardine. Bull. Ibaraki Fish. Exp. Stn., 36: 49-55.

FISHERIES RESEARCH AGENCY. 2007. Stock assessment and fisheries evaluation report in Japanese EEZ and Adjacent Waters. Fisheries Research Agency, Yokohama. $1258 \mathrm{p}$.

FUKUSHIMA, S. 1977. Synoptic analysis of migration and fishing conditions of saury in the northwest Pacific Ocean. Bull. Tohoku Reg. Fish. Res. Lab., 41: 1-70.

FUKUSHIMA, S., Y. WATANABE, and Y. OGAWA. 1990. Correspondence of spawned seasons to large, medium, and small size Pacific saury exploited in the northwestern Pacific Ocean. Bull. Tohoku Reg. Fish. Res. Lab., 52: $17-27$.

HEATH, M., H. ZENITANI, Y. WATANABE, R. KIMURA, and M. ISHIDA. 1998. Modelling the dispersal of larval Japanese sardine, Sardinops melanostictus, by the Kuroshio current in 1993 and 1994. Fish. Oceanogr., 7: 335-346. doi:10.1046/j.1365-2419.1998.00076.x

HOUDE, E. D. 1987. Fish early life dynamics and recruitment variability. Am. Fish. Soc. Symp., 2: 17-29.

HUBBS, C. L., and R. L. WISNER. 1980. Revision of the sauries (Pisces, Scomberesocidae) with descriptions of two new genera and one new species. Fish. Bull., 77: 521-566.

MINOBE, S., and N. MANTUA. 1999. Interdecadal modulation and interannual atmospheric and oceanic variability over the North Pacific. Prog. Oceanogr., 43: 163-192. doi:10.1016/S0079-6611(99)00008-7

NAKAI, Z. 1962. Preliminary studies on fluctuation in the Japanese sardine stock, mainly for the prewar period. Bull. Tokai Reg. Fish. Res. Lab., 9: 1-22.

NIHIRA, A., N. SUNO, and M. TAKAHASHI. 2003. Regime shift in ground fishes in the Sanriku and Joban water areas. Kaiyo Monthly, 35: 107-116.

NOTO, M., and I. YASUDA. 1999. Population decline of the Japanese sardine, Sardinops melanostictus, in relation to sea surface temperature in the Kuroshio Extension. Can. J. Fish. Aquat. Sci., 56: 973-983. doi:10.1139/ cjfas-56-6-973

OOZEKI, Y., Y. WATANABE, and D. KITAGAWA. 2004. Environmental factors affecting larval growth of Pacific saury, Cololabis saira, in the northwestern Pacific Ocean. Fish. Oceanogr., 13 (Suppl 1): 44-53. doi:10.1111/j.13652419.2004.00317.x

OOZEKI, Y., A. TAKASUKA, H. KUBOTA., and M. BARANGE. 2007. Characterizing spawning habitats of Japanese sardine (Sardinops melanostictus), Japanese anchovy (Engraulis japonicus), and Pacific round herring (Etrumeus teres) in the northwestern Pacific. Calif. Coop. Oceanic Fish. Invest. Rep., 48: 191-203.

SCHWARTZLOSE, R. A., J. ALHEIT, A. BAKUN, T. R. BAUMGARTNER, R. CLOETE, R. J. M. CRAWFORD, 
W. J. FLETCHER, Y. GREEN-RUIZ, P. HAGEN, T. KAWA S A K I, D. LLUCH-BELDA，S E. LLUCH-COTA, A. D. MACCALL, Y. MATSUURA, M. O. NEVAREZ-MARTINEZ, R. H. PARRISH, C. ROR, R. SERRA, K. V. SHUST, M. N. WARD, and J. Z. ZUZUNAGA. 1999. Worldwide large-scale fluctuation of sardine and anchovy populations. S. Afr. J. Mar. Sci., 21: 289-347.

SUGISAKI, H., Y. MATSUO, and K. YOKOUCHI. 1996. Distribution and recruitment of larval Japanese sardine in the Tohoku sea area. Bull. Jpn. Soc. Fish. Oceanogr., 60: $426-428$.

TAKAHASHI, M., and Y. WATANABE. 2004a. Growth-rate dependent recruitment of Japanese anchovy, Engraulis japonicus, in the Kuroshio-Oyashio transitional waters. Mar. Ecol. Prog. Ser., 266: 227-238. doi:10.3354/ meps 266227

2004b. Developmental and growth rates of Japanese anchovy Engraulis japonicus during metamorphosis in the Kuroshio-Oyashio transitional waters. Mar. Ecol. Prog. Ser., 282: 253-260. doi:10.3354/meps282253

TAKAHASHI, M., Y. WATANABE, T. KINOSHITA, and C. WATANABE. 2001. Growth of larval and juvenile Japanese anchovy, Engraulis japonicus, in the KuroshioOyashio transition region. Fish. Oceanogr., 10: 235-247. doi:10.1046/j.1365-2419.2001.00160.x

TAKAHASHI, M., H. NISHIDA, A. YATSU, and Y. WATANABE. 2008. Year-class strength and growth rates after metamorphosis of Japanese sardine Sardinops melanostictus in the western North Pacific Ocean during 1996-2003. Can. J. Fish. Aquat. Sci., 65: 1425-1434. doi:10.1139/ F08-063

TAKASUKA, A., and I. AOKI. 2006. Environmental determinants of growth rates for larval Japanese anchovy Engraulis japonicus in different waters. Fish. Oceanogr., 15: 139-149. doi:10.1111/j.1365-2419.2005.00385.x

TAKASUKA, A., Y. OOZEKI, and I. AOKI. 2007. Optimal growth temperature hypothesis: Why do anchovy flourish and sardine collapse or vice versa under the same ocean regime? Can. J. Fish. Aquat. Sci., 64: 768-776. doi:10.1139/F07-052

TAKASUKA, A., Y. OOZEKI, and H. KUBOTA. 2008. Multispecies regime shifts reflected in spawning temperature optima of small pelagic fish in the western North Pacific. Mar. Ecol. Prog. Ser, 360: 211-217. doi:10.3354/ meps07407

TIAN, Y., T. AKAMINE, and M. SUDA. 2003. Variations in the abundance of Pacific saury (Cololabis saira) from the northwestern Pacific in relation to oceanic-climate changes. Fish. Res., 60: 439-454. doi:10.1016/S0165-
7836(02)00143-1

TOHOKU NATIONAL FISHERIES RESEARCH INSTITUTE. 2007. Annual report of the research meeting on saury resources, 55: 1-286.

WADA, T. 1988. Population dynamics on Japanese sardine, Sardinops melanostictus, caught by the domestic purse seine fishery in the waters off the coast of southeastern Hokkaido. Bull. Hokkaido Reg. Fish. Res. Lab., 52: 1-138.

WATANABE, Y. 2007a. Two aspects of population decline of Japanese sardine. Nippon Suisan Gakkaishi, 73: 754-757. doi:10.2331/suisan.73.754

2007b. Latitudinal variation in recruitment dynamics of small pelagic fishes in the western North Pacific. J. Sea Res., 58: 46-58. doi:10.1016/j.seares.2007.02.002

WATANABE, Y., and N.C.H. LO. 1989. Larval production and mortality of Pacific saury (Cololabis saira) in the northwestern Pacific. Fish. Bull., 87: 601-613.

WATANABE, Y., and T. KUROKI. 1997. Asymptotic growth trajectories of larval sardine Sardinops melanostictus in the coastal waters off western Japan. Mar. Biol., 127: 369-378. doi: $10.1007 / \mathrm{s} 002270050023$

WATANABE, Y., and H. SAITO. 1998. Feeding and growth of juvenile sardine in the Pacific waters off central Japan. $J$. Fish Biol., 52: 519-533. doi:10.1111/j.1095-8649.1998. tb02014.X

WATANABE, Y., and M. NAKAMURA. 1998. Growth trajectory of the larval Japanese sardine, Sardinops melanostictus transported into the Pacific coastal waters off central Japan. Fish. Bull., 96: 900-907.

WATANABE, Y., H. ZENITANI, and R. KIMURA. 1995. Population decline of the Japanese sardine Sardinops melanostictus owing to recruitment failures. Can. J. Fish. Aquat. Sci., 52: 1609-1616. doi:10.1139/f95-154

1996. Offshore expansion of spawning of the Japanese sardine, Sardinops melanostictus, and its implication for egg and larval survival. Can. J. Fish. Aquat. Sci., 53: 55-61. doi:10.1139/cjfas-53-1-55

WATANABE, Y., Y. OOZEKI, and D. KITAGAWA. 1997. Larval parameters determining preschooling juvenile production of saury (Cololabis saira) in the northwestern Pacific. Can. J. Fish. Aquat. Sci., 54: 1067-1076. doi:10.1139/cjfas-54-5-1067

WATANABE, Y., Y. KURITA, M. NOTO, Y. OOZEKI, and D. KITAGAWA. 2003. Growth and survival processes of Pacific saury (Cololabis saira) in the KuroshioOyashio transitional waters. J. Oceanogr., 59: 403-414. doi:10.1023/A:1025532430674

YASUDA, I. 2003. Hydrographic structure and variability in the Kuroshio-Oyashio transition area. J. Oceanogr., 59: 389-402. doi:10.1023/A:1025580313836 